\title{
Diagnóstico ambiental da bacia hidrográfica contribuinte do reservatório tanque grande, Guarulhos (SP), com base em macroinvertebrados bentônicos
}

Este estudo teve por objetivo analisar a qualidade da água do Reservatório Tanque Grande-Montante e sub-bacias de contribuição, por meio, da estrutura da comunidade de macroinvertebrados bentônicos. Foram obtidas amostras de água e amostras de macroinvertebrados em seis pontos de coleta distribuídos na bacia em dois períodos, sendo um seco (agosto/2017) e outro chuvoso (dezembro/2017). Para a água foram determinadas temperatura, pH, oxigênio dissolvido, turbidez, condutividade elétrica, fósforo total, nitrogênio total e E.coli. Foram coletados 1.516 organismos, sendo Chironomidae (Insecta: Diptera) os mais abundantes na maioria dos pontos amostrados. Os resultados indicam processo de degradação ambiental oriundo de atividades de piscicultura e agropecuárias, conforme corroborado pelas altas concentrações de DBO e E.coli na maioria dos pontos analisados. Apesar do ambiente estudado estar localizado na "Área de Proteção Ambiental Cabuçu Tanque Grande", apresenta processos de degradação, indicando a necessidade de uma fiscalização mais rigorosa que evite a evolução das atividades antrópicas que contribuem para a degradação do ambiente.

Palavras-chave: Chironomidae; Tanytarsini; Orthocladiinae; Tanypodinae; Bioindicador.

\section{Environmental diagnosis of the watershed contributing to the tanque grande reservoir, Guarulhos (SP), based on benthic macroinvertebrates}

\begin{abstract}
This research aimed to analyze the Tanque Grande reservoir water quality through the study of benthonic macroinvertebrates community structure. Two yearly collects of benthonic macroinvertebrates have been done on six collect points, once in the dry season (2017 August) and another one in the wet season (2017 December). The following environmental parameters have been studied: water temperature, $\mathrm{pH}$, dissolved oxygen, water turbidity, electrical conductibility, total phosphorus, total nitrogen and E.coli. 1.516 organisms have been collected, registering the largest abundance of Chironomidade family (Diptera) in all the collect points and, most of all, degraded environmental parameters. This environmental degradation comes from the pisciculture and horticulture, as corroborated by the high concentrations of BOD and E.Coli in most of the analyzed points. It can be concluded that, although the studied environment is located in an area of environmental preservation, the "Environmental Protection Area Cabuçu Tanque Grande", shows signs of degradation, indicating the need of a more rigorous surveillance avoiding the progress of anthropic activities that are leading to environmental degradation.
\end{abstract}

Keywords: Chironomidae; Tanytarsini; Orthocladiinae; Tanypodinae; Bioindicador.

Topic: Hidrogeografia

Reviewed anonymously in the process of blind peer.

Carolina Leite de Moraes (iD)

Universidade Guarulhos, Brasil

http://lattes.cnpq.br/4114950964751145

http://orcid.org/0000-0002-8538-6111

carolinaleitedemoraes@gmail.com

Antônio Roberto Saad (iD)

Universidade de São Paulo, Brasil

http://lattes.cnpq.br/1578942616063181

http://orcid.org/0000-0002-9283-0620

asaad@usp.br

Fernanda Dall'Ara Azevedo (iD

Universidade Guarulhos, Brasil

http://lattes.cnpq.br/3803727119574160

http://orcid.org/0000-0002-2043-256X

fdallara.azevedo@gmail.com
Received: 10/08/2019

Approved: 28/09/2019

Edna Ferreira Rosini ib

Universidade Guarulhos, Brasil

http://lattes.cnpq.br/7671539590722012

http://orcid.org/0000-0002-4614-7839

edna.Ferreira@prof.ung.br
Referencing this:

MORAES, C. L.; SAAD, A. R.; AZEVEDO, F. D.; ROSINI, E. F.. Diagnóstico ambiental da bacia hidrográfica contribuinte do reservatório tanque grande, Guarulhos (SP), com base em macroinvertebrados bentônicos. Revista Ibero Americana de Ciências Ambientais, v.10, n.5, p.345359, 2019. DOI: http://doi.org/10.6008/CBPC2179$\underline{6858.2019 .005 .0030}$ 


\section{INTRODUÇÃO}

As bacias hidrográficas são unidades geográficas que, em geral, são aproveitadas para usos múltiplos de suas águas, tanto em rios como em reservatórios. O solo é ocupado por moradias (regulares ou não), atividades agropecuárias, mineração, transporte, lazer como esportivo, balneabilidade e 'pesque-pague'. Estas atividades em condições não controladas podem contribuir com o avanço da degradação ambiental, fazendo-se necessário o monitoramento dos recursos hídricos (MEDEIROS et al., 2016).

Dentre as ferramentas à disposição para a gestão de recursos hídricos, o monitoramento por meio de variáveis físicas e químicas permiti o conhecimento das condições da água no momento que são efetuadas as medições (análises físicas e químicas); já o biomonitoramento, com macroinvertebrados, destaca-se por refletir estados não mais existentes no momento da verificação, mas em condições pretéritas (LOBO et al., 2004; SCHILLER et al., 2017; ANA, 2011). Assim, quando estas ferramentas são utilizadas conjuntamente proporcionam uma visão mais completa do meio amostrado.

A comunidade de macroinvertebrados bentônicos é considerada um parâmetro favorável no biomonitoramento e avaliação da qualidade dos ecossistemas aquáticos pela facilidade de coleta, pelo hábito sedentário e pelo ciclo de vida relativamente longo que expressam as modificações do ambiente através da mudança na estrutura das populações e comunidades, possibilitando versatilidade nas respostas a diferentes tipos de alterações nas condições ambientais (CALLISTO et al., 2001; GOULART et al., 2003).

Estes organismos, desempenham fundamental papel na cadeia alimentar, além das atividades de escavação e decomposição da matéria orgânica que auxiliam na troca de nutrientes entre o sedimento e a água (TUNDISI et al., 2008; ESTEVES et al., 2011). A distribuição dos macroinvertebrados bentônicos nos ambientes aquáticos é influenciada pela composição da vegetação, profundidade da lâmina d'água, natureza química do substrato, disponibilidade de alimento, e uso e ocupação do entorno do ambiente aquático (OLIVEIRA et al., 2005; ESTEVES et al., 2011).

Assim, o objetivo deste trabalho é avaliar a qualidade da água da bacia contribuinte do Reservatório Tanque Grande, localizado no município de Guarulhos, SP, por meio da análise conjunta da estrutura da comunidade de macroinvertebrados bentônicos e dos parâmetros físicos e químicos da água, tendo como base os aspectos do meio físico e do uso e ocupação da terra.

\section{MATERIAIS E MÉTODOS}

\section{Caracterização da área de estudo}

O reservatório Tanque Grande está localizado no munícipio de Guarulhos-SP, precisamente, na porção sudeste a montante da microbacia Tanque Grande, que, é abastecido por 5 sub-bacias tributárias (Figura 1). As características geométricas e os índices geomorfológicos da microbacia Tanque GrandeMontante estão sumarizados no Quadro 1. As águas do reservatório Tanque Grande são enquadradas na classe especial, por estar situado dentro de uma Área de Proteção Ambiental, a APA Tanque Grande. Suas águas são responsáveis pelo abastecimento de $3 \%$ da população do município e também destinadas à 
Diagnóstico ambiental da bacia hidrográfica contribuinte do reservatório tanque grande, Guarulhos (SP), com base em macroinvertebrados bentônicos

irrigação, piscicultura e ao lazer (SAAD et al., 2007).

Quadro 1: Características morfométricas da Microbacia Tanque Grande - Montante.

\begin{tabular}{|l|l|}
\hline \multicolumn{2}{|l|}{ Características Geométricas } \\
\hline Comprimento: $2650 \mathrm{~m}$ & Largura máxima: $3950 \mathrm{~m}$ \\
\hline Perímetro: $12.738,76$ & Área da bacia: 774,55 há \\
\hline Altitude máxima: $1080 \mathrm{~m}$ & Altitude mínima: $830 \mathrm{~m}$ \\
\hline Desnível: $250 \mathrm{~m}$ & \multicolumn{2}{|l}{} \\
\hline Índices Geomorfológicos & Circularidade: $0,6($ baixa) \\
\hline Área da bacia: $7.745 .527,59 \mathrm{~m}^{2}$ & Densidade de drenagem $\left(\mathrm{km}^{2} / \mathrm{km}^{2}\right): 3,24$ \\
\hline Comprimento da rede de drenagem: $25,1 \mathrm{~km}$ & Densidade do talvegue principal: $120 \mathrm{~m}$ \\
\hline Comprimento do talvegue principal $(\mathrm{m}): 4.666,69 \mathrm{~m}$ & \\
\hline Declividade do talvegue principal: $2,57 \%$ & \\
\hline
\end{tabular}

Fonte: Oliveira et al. (2005).

O clima da área de estudo é denominado como mesotérmico brando úmido, com um a dois meses secos, com temperatura média anual de 19ํㅡ, precipitação pluviométrica entre 1.250 a $1.500 \mathrm{~mm}$ no ano e umidade relativa do ar inferior a $20 \%$, caracterizando inverno seco e verão chuvoso. Sendo que os meses referente ao período de estudo registrou precipitações mensais inferiores a $150 \mathrm{~mm}$, compreendendo os meses de junho $(0,8 \mathrm{~mm})$, agosto $(60,5 \mathrm{~mm})$ e setembro $(11,1 \mathrm{~mm})$ no período de estiagem. Já o período chuvoso, outubro a março, registrou precipitações maiores que $150 \mathrm{~mm}$, com máxima de $450 \mathrm{~mm}$ no mês de janeiro de 2017 (INMET, 2017). O relevo da área estudada é composto por serras, morros e planícies pluviais, com predominância de latossolo vermelho-amarelo, cambissolo em terrenos com declive e gleissolo, nas planícies fluviais (ANDRADE et al., 2008). Em relação ao uso e ocupação da terra, Santos (2005) e Saad et al. (2007) mencionam atividades como, criações de gado e aves, pisciculturas, horticultura e fruticultura, plantações de bambu e produção de mel. São encontradas, também, áreas de práticas de turismo rural e lazer, como clubes e pesqueiros (PIASENTIN et al., 2009).

\section{Delineamento Amostral}

As coletas foram realizadas em duas campanhas no ano de 2017, uma no período seco (agosto) e outra no período chuvoso (dezembro). As amostragens foram realizadas em seis pontos, sendo os pontos, conforme Tabela 1 , Erro! Fonte de referência não encontrada. e Figura 2.

Tabela 1: Coordenadas geográficas da distribuição dos pontos de coleta na microbacia Tanque-Grande, Guarulhos, SP.

\begin{tabular}{|c|c|c|c|}
\hline \multirow{2}{*}{$\begin{array}{l}\text { Pontos de } \\
\text { coleta }\end{array}$} & \multicolumn{2}{|l|}{ Coordenadas } & \multirow[t]{2}{*}{ Descrição dos pontos de coleta } \\
\hline & Latitude & Longitude & \\
\hline Ponto 1 & $\begin{array}{ll}23 & k \\
350581.00 \mathrm{E}\end{array}$ & $\begin{array}{l}7415234.00 \\
S\end{array}$ & $\begin{array}{l}\text { Sistema lótico, tributário da Sub-bacia A. Água com aspecto límpido, com pedras e } \\
\text { sedimento fino de fundo. }\end{array}$ \\
\hline Ponto 2 & $\begin{array}{lr}23 & \mathrm{~K} \\
349805.00 \mathrm{E}\end{array}$ & $\begin{array}{l}7414929.00 \\
S\end{array}$ & $\begin{array}{l}\text { Sistema lótico, tributário da Sub-bacia B. Água com aspecto turvo, com sedimento } \\
\text { fino de fundo e vegetação no entorno do córrego. }\end{array}$ \\
\hline Ponto 3 & $\begin{array}{lr}23 & K \\
350520.00 \mathrm{E}\end{array}$ & $\begin{array}{l}7414513.00 \\
S\end{array}$ & $\begin{array}{l}\text { Sistema lótico, tributário da Sub-bacia C. Água com aspecto límpido, na lateral de uma } \\
\text { via de acesso, sedimento fino e barrento de fundo com vegetação alta no entorno e } \\
\text { dentro da água em um dos lados e erosão nas margens no outro lado. }\end{array}$ \\
\hline Ponto 4 & $\begin{array}{lr}23 & \mathrm{~K} \\
350701.00 \mathrm{E}\end{array}$ & $\begin{array}{l}7414598.00 \\
S\end{array}$ & $\begin{array}{l}\text { Sistema lênticos, reservatório, influenciado pelas sub-bacias A e B. Água com aspecto } \\
\text { turvo, pedras e sedimento barroso de fundo. }\end{array}$ \\
\hline Ponto 5 & $\begin{array}{lr}23 & K \\
350722.00 \mathrm{E}\end{array}$ & $\begin{array}{l}7414264.00 \\
S\end{array}$ & $\begin{array}{l}\text { Sistema lêntico, reservatório na Sub-bacia D. Água com aspecto límpido, macrófitas } \\
\text { na água, pedra, cascalhos e sedimento fino de fundo. }\end{array}$ \\
\hline Ponto 6 & $\begin{array}{lr}23 & \mathrm{~K} \\
350949.00 \mathrm{E}\end{array}$ & $\begin{array}{l}7414239.00 \\
S\end{array}$ & $\begin{array}{l}\text { Sistema lêntico, reservatório na Sub-bacia E. Água com aspecto turvo, com vegetação } \\
\text { alta dentro da água e no entorno e sedimento fino de fundo e pedras. }\end{array}$ \\
\hline
\end{tabular}




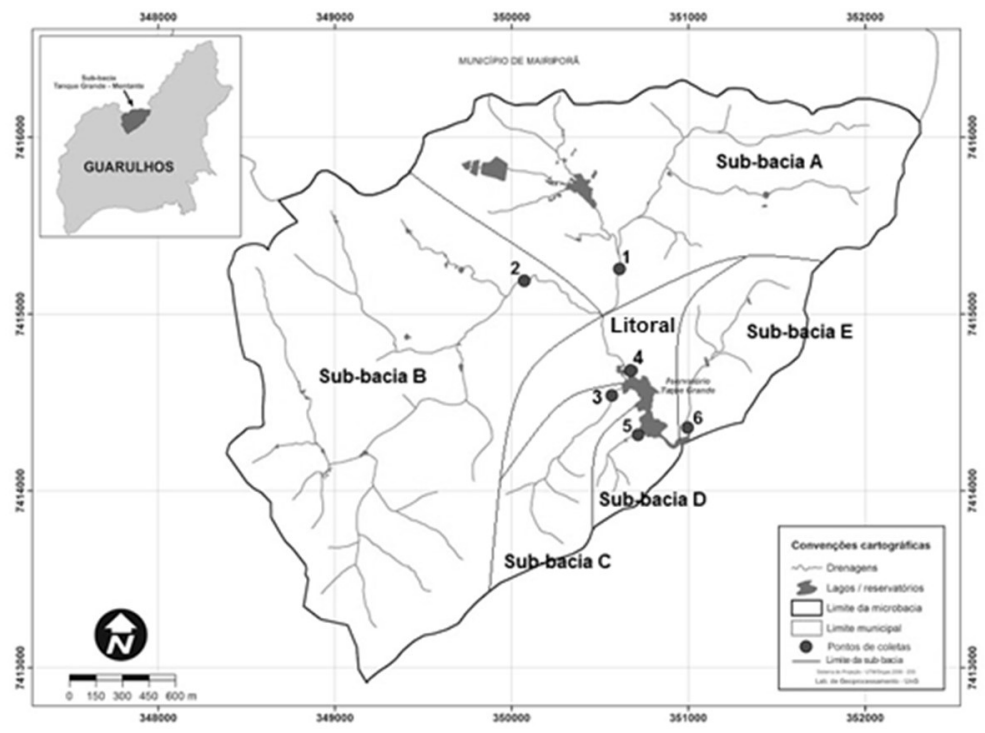

Figura 1: Localização dos pontos de coletas nas sub-bacias e no Reservatório Tanque Grande. Fonte: Mapa modificado de Piasentin et al. (2009).

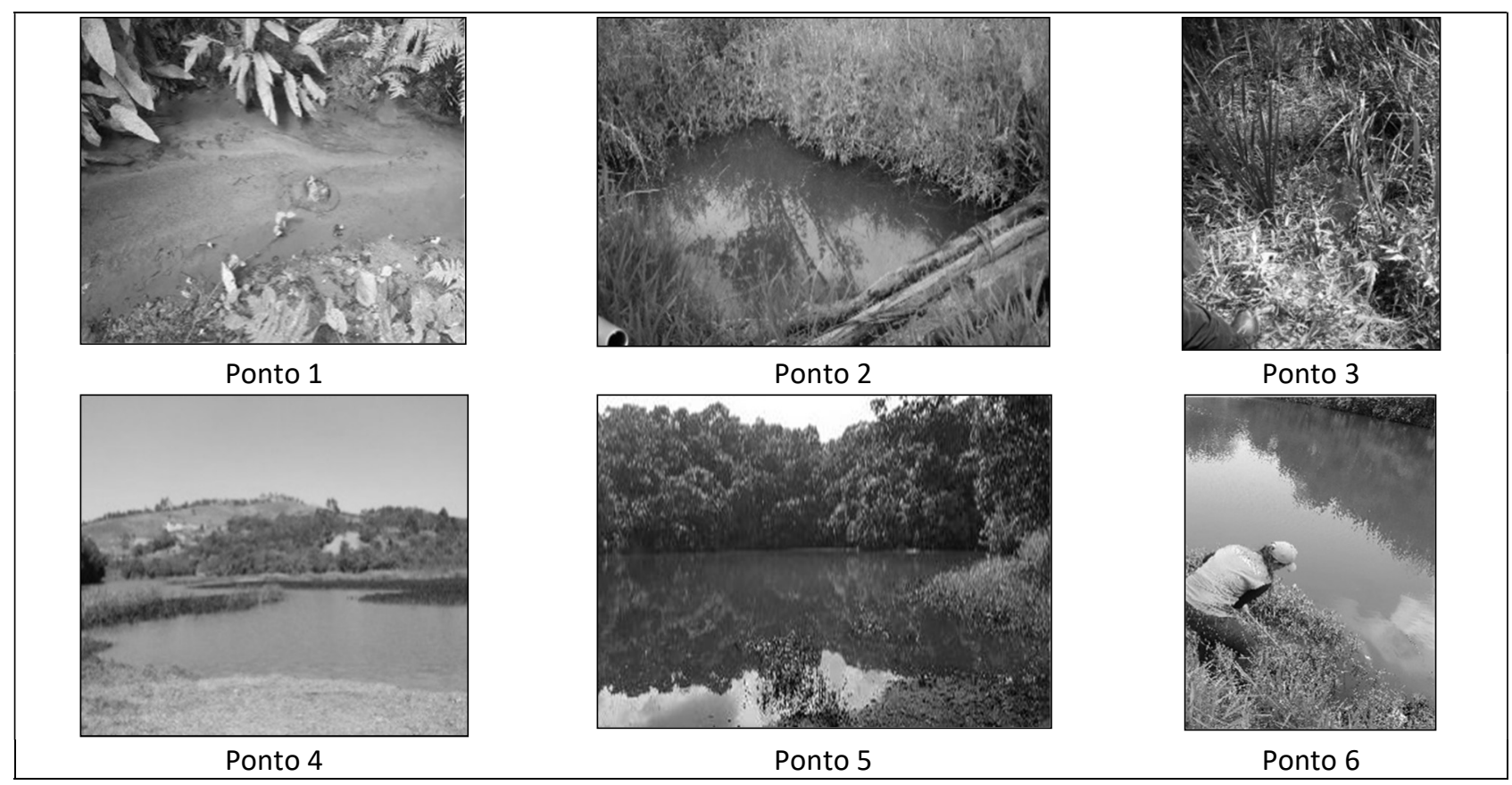

Figura 2: Imagens dos pontos de coletas nas sub-bacias e no Reservatório Tanque Grande. Fonte: Moraes (2019).

\section{Coleta e tratamento dos macroinvertebrados bentônicos}

A comunidade bentônica foi coletada com uma rede manual do tipo D com malha de $250 \mu \mathrm{m}$, em cada ponto foi feito o arraste da rede no substrato, em um trecho de um metro, em triplicata. O material foi armazenado em sacos plásticos identificados e fixados com álcool 70\%. Em laboratório o material foi lavado com o auxílio de peneira, triado e identificado sob estereomicroscópio, com auxílio de chaves de identificação: Hamada et al. (2014), Mugnai et al. (2010), sendo os organismos identificados até o nível de família e ao nível de subfamília, e tribos para os táxons da Família Chironomidae.

Para a análise dos dados bióticos foram avaliados riqueza de famílias, índice de Diversidade $\left(\mathrm{H}^{\prime}\right)$ de Shannon Wienner (WEAVER, 1963); abundância e avaliada, as espécies descritoras do ambiente, considerando-se um nível de corte de $2 \%$ da abundância total da comunidade de macroinvertebrados das 
Diagnóstico ambiental da bacia hidrográfica contribuinte do reservatório tanque grande, Guarulhos (SP), com base em macroinvertebrados bentônicos

MORAES, C. L.; SAAD, A. R.; AZEVEDO, F. D.; ROSINI, E. F.

duas épocas estudadas. Este nível de corte selecionou espécies que contribuíram com 88\% para a abundância total (SOMMER et al., 1993).

\section{Análise de água}

As coletas de água foram realizadas de acordo com o Guia Nacional de Coleta e Preservação de amostras da Agência Nacional de Águas (ANA, 2011). As variáveis de temperatura da água, potencial hidrogeniônico $(\mathrm{pH})$, condutividade elétrica $\left(\mu \mathrm{S} / \mathrm{cm}^{-1}\right)$, turbidez e oxigênio dissolvido $\left(\mathrm{mgL}^{-1}\right)$ foram obtidos in loco através do medidor multiparâmetros modelo SX751 com medições em triplicata, enquanto os demais parâmetros foram analisados conforme APHA (Quadro 2). Os resultados das varáveis físicas, químicas e biológicas da água foram comparados aos limites estabelecidos pela resolução CONAMA 357/2005 para corpos de água classificados na classe 1 , por ser a classificação das águas que melhor se enquadra aos corpos d'água estudados.

Quadro 2: Metodologia de análise dos Parâmetros Físico-químicos.

\begin{tabular}{|c|c|}
\hline Parâmetro & Método de análise \\
\hline Fósforo Total (PT) & $\begin{array}{l}\text { APHA. Standard Methods for the Examination of Water and Wastewater } 22^{\text {nd }} \text { Ed }- \text { método } \\
4500-P \text { E }\end{array}$ \\
\hline Nitrogênio Total & $\begin{array}{l}\text { APHA. Standard Methods for the Examination of Water and Wastewater; } 22^{\text {nd }} \text { Ed, método } 4500 \\
\text { C. 4-105. Método do Persulfato }\end{array}$ \\
\hline $\begin{array}{l}\text { Coliformes Termotolerantes (E. } \\
\text { coli) }\end{array}$ & $\begin{array}{l}\text { APHA. Standard Methods for the Examination of Water and Wastewater (SMEWW) } 22^{\text {nd }} \text { Ed- } \\
\text { método } 9222\end{array}$ \\
\hline $\begin{array}{l}\text { Demanda Bioquímica de } \\
\text { Oxigênio (DBO) }\end{array}$ & Analisadores eletrônicos de DBO via método manométrico (VELP, 2016) \\
\hline Sólidos Totais & $\begin{array}{l}\text { APHA. Standard Methods for the Examination of Water and Wastewater (SMEWW) } 22^{\text {nd }} \text { Ed - } \\
\text { método } 2540 \mathrm{~B}\end{array}$ \\
\hline
\end{tabular}

\section{Elaboração do mapa de uso e ocupação da terra}

$\mathrm{Na}$ elaboração do mapa de uso e ocupação da terra, foi realizada a interpretação de foto e reconhecimento da cobertura homogênea da terra e feito o mapeamento por meio da digitalização de camadas na imagem orbital. A montagem da base de dados espaciais foi gerada em ambiente SIG através da plataforma ArcGIS 10.3 da empresa ESRI, 2014, compatível com a escala 1: 24.000 com projeção UTM e datum SIRGAS 2.000.

\section{Análise estatística}

Para a avaliação conjunta das variáveis abióticas e bióticas foi utilizada a análise de correspondência canônica (CCA). Para esta análise foi utilizada matriz de covariância, sendo a matriz de dados bióticos e abióticos transformada pela amplitude de variação 'ranging' ([x-xmin) /(xmax-xmin)]). Para testar o nível de significância dos dois primeiros eixos canônicos foi utilizado o teste de Monte Carlo (999 permutações; $p \leq$ $0,05)$, que determina se há probabilidade de os autovalores terem distribuição ao acaso. As análises multivariadas foram realizadas pelo programa PC-ORD, versão 6.1 para Windows (MCCUNE et al., 2011). Nas análises multivariadas, foram consideradas correlações significativas aquelas que apresentarem $r>0,5$ com os eixos 1 e 2 da ordenação. 


\section{RESULTADOS}

\section{Avaliação física dos ambientes: uso e ocupação da terra}

A Bacia Hidrográfica do Tanque Grande é caracterizada por regiões de campo e edificações rurais e possui uma rede hidrográfica composta por 5 sub-bacias que alimentam o Reservatório Tanque Grande. A caracterização do uso e ocupação da terra nessas áreas foi identificada com as classes: Floresta (73,08\% da área), edificações rurais que englobam as vilas, estradas, aldeias, chácaras e indústrias (14,99\%), áreas de vegetação baixa e campo $(10,10 \%)$, lagos $(1,20 \%)$ e áreas identificadas com cultivo $(0,63 \%)$ da ocupação nesta bacia, conforme visualizado no mapa de uso e ocupação da terra (Erro! Fonte de referência não encontrada.). As classes de edificações rurais somadas com a área de cultivo correspondem a mais de $15 \%$ das áreas em conflito de uso, apesar de 73,08\% da área corresponder a florestas. Quando analisado o uso e ocupação do solo por sub-bacia, observa-se que a sub-bacia $D$ foi a que apresentou a maior área com influência antrópica (área de edificações rurais $32.17 \%$, campo $30.15 \%$ e cultivo $0.58 \%$ ) e a menor área ocupada por florestas (19.77\%), enquanto nas demais sub-bacias a área ocupada por floresta foi sempre maior que a área ocupada por atividade humana (tabela 2).

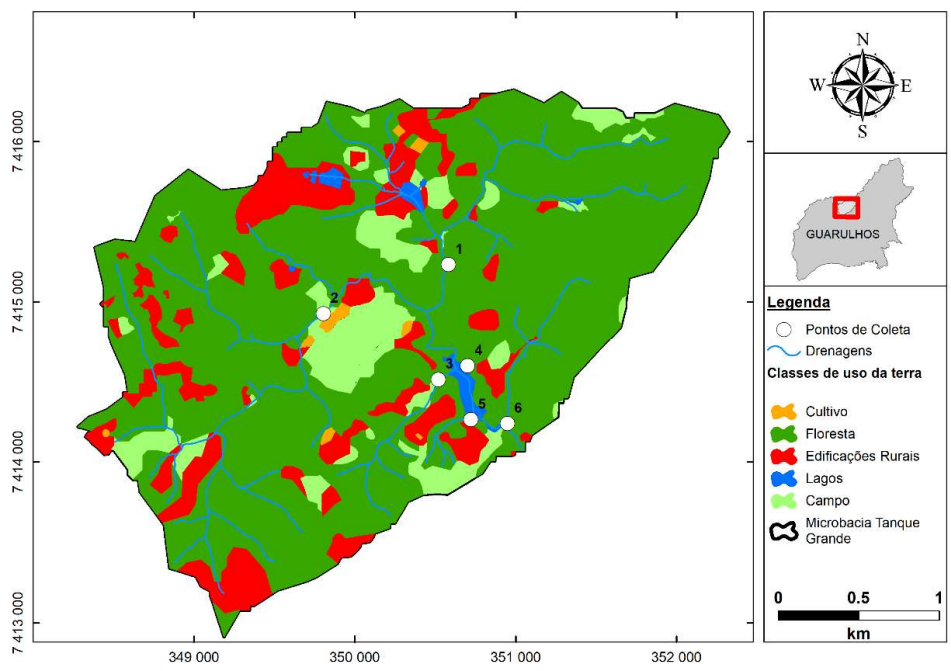

Figura 2: Uso e ocupação do solo da bacia hidrográfica Tanque Grande, Guarulhos, SP. Fonte: Moraes (2019).

Tabela 2: Uso e ocupação da terra das sub-bacias da microbacia Tanque Grande-Montante.

\begin{tabular}{|l|l|l|l|l|l|l|}
\hline Pontos de coleta & Sistema & Sub-bacia & Floresta (\%) & Edificações Rurais (\%) & Campo (\%) & Cultivo (\%) \\
\hline 1 & Lótico & A & $76.57 \%$ & $13.27 \%$ & $8.23 \%$ & $0.41 \%$ \\
\hline 2 & Lótico & B & $69.20 \%$ & $19.36 \%$ & $10.52 \%$ & $0.85 \%$ \\
\hline 3 & Lótico & C & $49.83 \%$ & $24.89 \%$ & $17.97 \%$ & $0.24 \%$ \\
\hline 4 & Lêntico & Litoral & $54.20 \%$ & $5.49 \%$ & $32.51 \%$ & $0.66 \%$ \\
\hline 5 & Lêntico & D & $19.77 \%$ & $32.17 \%$ & $30.15 \%$ & $0.58 \%$ \\
\hline 6 & Lêntico & E & $87.72 \%$ & $5.67 \%$ & $1.78 \%$ & $0.00 \%$ \\
\hline
\end{tabular}

É importante ressaltar que as áreas de campo e cultivo apresentam riscos à qualidade da água uma vez que a aplicação de pesticidas e fertilizantes amplamente utilizados na agricultura e a remoção de vegetação natural bem como resíduos derivados da criação de animais, também observadas nessas área de campo são tidos como as principais causas de perdas de qualidade de água (EMBRAPA, 2002). Além disso, as áreas de edificações rurais, mesmo com menor ocupação, também podem alterar a qualidade das águas pela falta de infraestrutura adequada, conforme observado por Piasentin et al. (2009) na mesma área de estudo. 


\section{Avaliação físico-química e microbiológica da água}

$\mathrm{O}$ pH (Tabela 3) registrou valores entre 6,73 e 7,51 no período seco, e no período chuvoso seus valores estiveram entre 6,40 e 7,43. Tanto no período chuvoso como no seco, os menores valores do pH foram registrados no ponto 3. O oxigênio dissolvido (Tabela 3), compreendeu valores entre 7,38 mg/L a 12,2 $\mathrm{mg} / \mathrm{L}$ para o período seco, e $6,5 \mathrm{mg} / \mathrm{L}$ a $7,7 \mathrm{mg} / \mathrm{L}$ para o período chuvoso. No período seco os maiores valores de oxigênio dissolvido foram registrados no ponto $6(12,2 \mathrm{mg} / \mathrm{L})$ e os menores no ponto 3 (7,38 $\mathrm{mg} / \mathrm{L})$, semelhantemente, no período chuvoso o ponto 3 registrou os menores valores $(6,5 \mathrm{mg} / \mathrm{L})$ e o ponto 5 os maiores (7,7 mg/L). A Demanda Biológica de Oxigênio (Tabela 3), apresentou valores para o período de seca, entre 0 a 2,4 mg/L e para o período chuvoso valores entre 2,1 a 14,2 mg/L, ou seja, valores superiores ao registrado no período seco. Isto se deve as maiores precipitações nesse período que carreia material orgânico para o corpo hídrico aumentado a decomposição do material orgânico.

Para a condutividade elétrica (Tabela 3 ) foram registrados valores entre $45 \mu \mathrm{S} . \mathrm{cm}^{-1}$ a $70 \mu \mathrm{S} . \mathrm{cm}^{-1}$ no período seco e $56 \mu \mathrm{S} . \mathrm{cm}^{-1}$ a $90 \mu \mathrm{S} . \mathrm{cm}^{-1}$ no período chuvoso. Os valores de Sólidos totais (Tabela 3) estiveram entre $25 \mathrm{mg} / \mathrm{L}$ e $27 \mathrm{mg} / \mathrm{L}$ no período seco e $23 \mathrm{mg} / \mathrm{L}$ e $45 \mathrm{mg} / \mathrm{L}$ no período chuvoso, ou seja, favorecendo baixos valores de turbidez (Tabela 3). Essa por sua vez, apresentou valores entre 1,8 a 20 UNT no período seco e, no período chuvoso valores entre 0,85 a 4,73 UNT.

Tabela 3: Resultado dos parâmetros analisados da água, para os pontos de coleta, com limites estabelecidos pela Resolução CONAMA 357/05 para água doce de Classe 1.

\begin{tabular}{|c|c|c|c|c|c|c|c|c|c|c|c|c|c|c|c|c|c|c|c|c|c|}
\hline \multirow[b]{2}{*}{ Pontos } & \multirow[b]{2}{*}{ Sistemas } & \multicolumn{2}{|c|}{$\mathrm{T}\left({ }^{\circ} \mathrm{C}\right)$} & \multicolumn{2}{|c|}{$\begin{array}{c}\text { OD } \\
(\mathrm{mg} / \mathrm{L})\end{array}$} & \multicolumn{2}{|c|}{$\mathrm{pH}$} & \multicolumn{2}{|c|}{$\begin{array}{c}\mathrm{NT} \\
(\mathrm{mg} / \mathrm{L})\end{array}$} & \multicolumn{2}{|c|}{$\begin{array}{c}\text { PT } \\
\text { (mg/L) }\end{array}$} & \multicolumn{2}{|c|}{$\begin{array}{c}\text { DBO } \\
\text { (mg/L) }\end{array}$} & \multicolumn{2}{|c|}{$\begin{array}{c}\mathrm{ST} \\
(\mathrm{mg} / \mathrm{L})\end{array}$} & \multicolumn{2}{|c|}{$\begin{array}{c}\text { TU } \\
\text { (UNT) }\end{array}$} & \multicolumn{2}{|c|}{$\begin{array}{c}\text { CE } \\
(\mu \mathrm{s} / \mathrm{cm})\end{array}$} & \multicolumn{2}{|c|}{$\begin{array}{c}\text { E. Coli } \\
\text { UFC/100mI }\end{array}$} \\
\hline & & $s$ & C & S & C & $S$ & C & $s$ & C & $S$ & $\mathrm{C}$ & $\mathrm{S}$ & $\mathrm{C}$ & $S$ & $\mathrm{C}$ & $s$ & $\mathrm{C}$ & $S$ & C & $S$ & C \\
\hline Ponto 1 & Lótico & 16.8 & 19.6 & 8.74 & 7.2 & 7.13 & 6.9 & 0.05 & 0.27 & 0.007 & 0.007 & 0 & $\underline{11.5}$ & 25 & 23 & 1.8 & 0.85 & 58.1 & 69.6 & $\underline{790}$ & $\underline{345}$ \\
\hline Ponto 2 & Lótico & 16.8 & 19.2 & 9.54 & 7.6 & 7.51 & 6.9 & 0.05 & 0.05 & 0.04 & 0.007 & 0 & $\underline{12}$ & 16 & 24 & 1.9 & 3.57 & 45 & 56 & $\underline{215}$ & 170 \\
\hline Ponto 3 & Lótico & 18.9 & 19.3 & 7.38 & 6.5 & 6.73 & 6.4 & 0.05 & 0.07 & 0.007 & 0.007 & 1 & $\underline{7.6}$ & 27 & 45 & 1.8 & 4.73 & 69.6 & 90.7 & $\underline{740}$ & $\underline{440}$ \\
\hline Ponto 4 & Lêntico & 20.6 & 24.7 & 8.78 & 6.7 & 7.45 & 6.93 & 0.05 & 0.34 & 0.007 & 0.007 & 0 & $\underline{12.6}$ & 20 & 14 & 19.9 & 2.76 & 56.8 & 64.1 & 40 & 50 \\
\hline Ponto 5 & Lêntico & 22.3 & 24.4 & 11.7 & 7.7 & 7.31 & 7.43 & 0.94 & 0.05 & 0.007 & 0.007 & 2.4 & $\underline{14.2}$ & 5 & 7 & 5.8 & 3.63 & 54.2 & 88.2 & $\underline{210}$ & $\underline{270}$ \\
\hline Ponto 6 & Lêntico & 22.9 & 24.9 & 12.2 & 7.6 & 7.45 & 7.23 & 0.7 & 0.77 & 0.007 & 0.007 & 1.3 & 2.1 & 3 & 2 & 3.7 & 1.66 & 48.2 & 67.1 & 155 & 60 \\
\hline \multicolumn{2}{|c|}{$\begin{array}{c}\text { CONAMA -357/05 } \\
\text { Classe } 1\end{array}$} & \multicolumn{2}{|c|}{ - } & \multicolumn{2}{|c|}{$>6 \mathrm{mg} / \mathrm{L}$} & \multicolumn{2}{|c|}{6,0 a 9,0} & \multicolumn{2}{|c|}{$\leq 3,7 \mathrm{mg} / \mathrm{L}$} & $\begin{array}{r}0,1 \mathrm{~m} \\
\text { Lóti } \\
<0,020 \\
\text { Lênt }\end{array}$ & $\begin{array}{l}\mathrm{g} / \mathrm{L} \\
\mathrm{ico} \\
\mathrm{mg} / \mathrm{L} \\
\text { ico }\end{array}$ & \multicolumn{2}{|c|}{$<3 \mathrm{mg} / \mathrm{L}$} & \multicolumn{2}{|c|}{$500 \mathrm{mg} / \mathrm{L}$} & \multicolumn{2}{|c|}{$<40$ UNT } & & & \multicolumn{2}{|c|}{$<200$} \\
\hline
\end{tabular}

T: Temperatura, OD: Oxigênio Dissolvido, pH: Potencial Hidrogeniônico, NT: Nitrogênio Total, PT: Fósforo Total, DBO: Demanda Bioquímica de Oxigênio, ST: Sólidos Totais, CE: Condutividade Elétrica, TU: Turbidez. 1o campanha de coleta no mês de Agosto (período de seco - S) e 20 campanha de coleta no mês de Dezembro (período de chuva - C). Números em negrito e sublinhado indicam valores acima do estipulado pela legislação.

O fósforo total e o nitrogênio total são parâmetros importantes para avaliação da degradação do corpo hídrico. Neste trabalho os resultados demonstraram baixas concentrações desses nutrientes no corpo d'água durante todo o período analisado, com valores de fósforo total inferiores a 0,020 $\mathrm{mg} / \mathrm{L}$ para ambientes lênticos e de 0,1 mg/L para ambientes lóticos e valores de nitrogênio total inferior a $1 \mathrm{mg} / \mathrm{L}$. Embora baixa, é possível observar elevado aumento na concentração do fósforo total, no período seco, no ponto 2 , provavelmente, devido as atividades de agricultura a montante deste ponto. Em relação ao nitrogênio total, também é possível observar aumento da concentração deste nutriente nos pontos 5 (período seco) e 6 (períodos seco e chuvoso) (Tabela 3). Neste trabalho registrou-se valores entre 40 a $790 \mathrm{UFC} / 100 \mathrm{ml}$ no período seco e no período chuvoso os valores estiveram entre 50 a $440 \mathrm{UFC} / 100 \mathrm{ml}$. Os maiores valores foram 
observados nos pontos 1 e 3 em ambos os períodos sazonais, excedendo o limite máximo estabelecido pela resolução CONAMA 357/2005 que é de 200 UFC/100ml.

\section{Dados bióticos}

Os resultados avaliados para os atributos de riqueza $(\mathrm{S})$ e diversidade $\left(\mathrm{H}^{\prime}\right)$ da comunidade bentônica indicaram que, de maneira geral, os maiores valores para riqueza e diversidade de famílias foram registrados no período de chuva e no ponto 6 do período de seca, conforme (Figura 4).
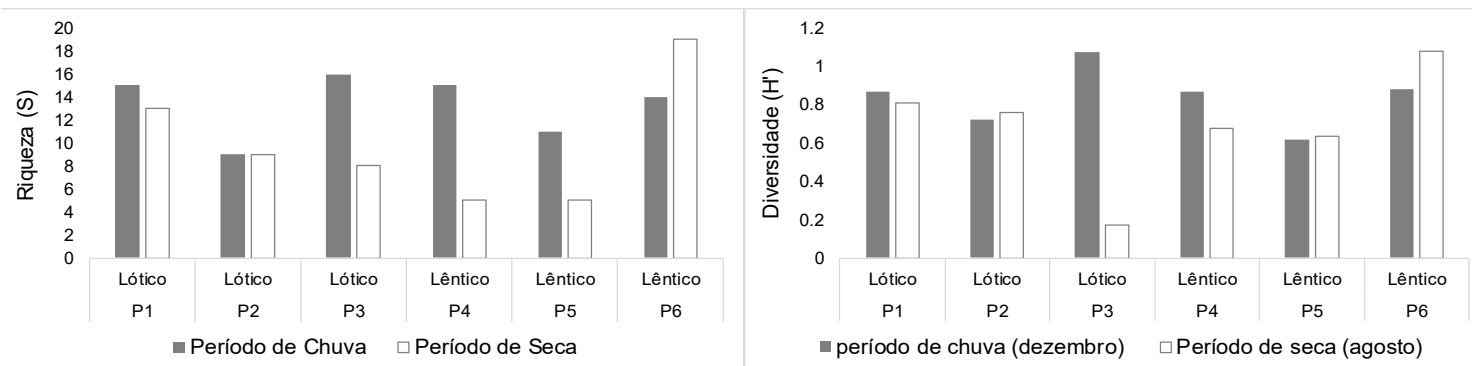

Figura 4: Valores de Riqueza (S) e Diversidade ( $H^{\prime}$ ) da fauna bentônica dos pontos amostrados no reservatório Tanque Grande e nas sub-bacias hidrográficas da Bacia Tanque Grande.

Foram coletados 1.516 indivíduos (Tabela 4), distribuídos nos Filos Annelida (classes Hirudinae e Oligochaeta), Crustacea (Decapoda), Mollusca (classes Bivalvia e Gastropoda) e Arthropoda (classe Insecta). As ordens com maior número de famílias foram aquelas da classe insecta sendo: Diptera, com 13 famílias, seguida das ordens Odonada, seis famílias, Coleoptera e Heteroptera com 5 famílias cada e Ephemeroptera com 4 famílias. A classe Oligochaeta foi representada pela família Tubificídae, Decapoda pelas famílias Trichodactylidae e Palaemonidae, Bivalvia pelas famílias, Sphaeriidae e Corbiculidae, enquanto que Gastropoda foi representada pela família Planorbidae e Physidae, ambas com pouca abundância nas amostras.

Tabela 4: Identificação e ocorrência de macroinvertebrados aquáticos coletados em seis pontos nas sub bacias e no reservatório Tanque Grande, no período seco (agosto) e no período chuvoso (dezembro) de 2017, sendo os pontos (1, 2 e 3 - Lótico) e os pontos (4, 5 e 6 - Lêntico).

\begin{tabular}{|c|c|c|c|c|c|c|c|c|c|c|c|c|}
\hline \multirow[t]{2}{*}{ TÁXONS } & \multicolumn{6}{|c|}{ Período de Seca } & \multicolumn{6}{|c|}{ Período Chuvoso } \\
\hline & P1 & $\mathrm{P} 2$ & P3 & P4 & $\mathrm{P} 5$ & P6 & P1 & $\mathrm{P} 2$ & P3 & $\mathrm{P} 4$ & P5 & P6 \\
\hline \multicolumn{13}{|l|}{ ANNELLIDA } \\
\hline Classe Hirudinea & & & 1 & & 1 & & & 1 & 5 & & 1 & \\
\hline \multicolumn{13}{|l|}{ Classe Oligochaeta } \\
\hline \multicolumn{13}{|l|}{ Ordem Haplotaxida } \\
\hline Família Tubificidae & 10 & & 1 & & 3 & & 2 & 5 & 6 & 3 & & \\
\hline \multicolumn{13}{|l|}{ MOLLUSCA } \\
\hline \multicolumn{13}{|c|}{ Classe Gastropoda } \\
\hline \multicolumn{13}{|c|}{ Ordem Basommatophora } \\
\hline Família Planorbidae & & 1 & & & & & & & & & & \\
\hline Família Physidae & & & & & & & 1 & & & & & \\
\hline \multicolumn{13}{|l|}{ Classe Bivalvia } \\
\hline \multicolumn{13}{|l|}{ Ordem Veneroida } \\
\hline Família Sphaeriidae & & & 3 & & & & & & 3 & & & \\
\hline Família Corbiculidae & & & & & 1 & & & & & & & \\
\hline \multicolumn{13}{|l|}{ CRUSTACEA } \\
\hline \multicolumn{13}{|l|}{ Classe Malacostraca } \\
\hline Ordem Decapoda & & & & & & & & & & & & \\
\hline
\end{tabular}




\begin{tabular}{|c|c|c|c|c|c|c|c|c|c|c|c|c|}
\hline Família Trichodactylidae & 1 & & & & & & & & & & & 1 \\
\hline Família Palaemonidae & & & & & & & & 3 & & & & \\
\hline \multicolumn{13}{|l|}{ ARTHROPODA } \\
\hline \multicolumn{13}{|l|}{ Classe Insecta } \\
\hline \multicolumn{13}{|l|}{ Ordem Odonata } \\
\hline Família Gomphidae & & & & & & & 7 & 1 & & & & \\
\hline Família Aeshnidae & 3 & & & & & 15 & 1 & & & & & \\
\hline Família Dicteriadidae & & & & & & & 2 & & 1 & 4 & 1 & 21 \\
\hline Família Libellulidae & 3 & & 5 & & & 22 & 1 & & & & & \\
\hline Família Zygoptera & & & & & & 8 & & 1 & & & & \\
\hline Família Coenagrionidae & & & 1 & & & 1 & & & & & & \\
\hline \multicolumn{13}{|l|}{ Ordem Díptera } \\
\hline \multicolumn{13}{|l|}{ Família Chironomidae } \\
\hline \multicolumn{13}{|l|}{ Subfamília Chironominae } \\
\hline Tribo Chironomini & 37 & 10 & & 7 & & 3 & 25 & 14 & 3 & 3 & 110 & 43 \\
\hline Tribo Tanytarsini & 103 & & & & & & 7 & 1 & 4 & 5 & 13 & 6 \\
\hline Subfamília Tanypodinae & 24 & 10 & 3 & & 3 & 36 & 20 & 12 & 12 & 17 & 101 & 21 \\
\hline Subfamília Orthocladiinae & 84 & 8 & 184 & 6 & & 15 & 29 & 1 & 14 & 7 & 16 & 6 \\
\hline Família Simulidae & 22 & & & & & & & & & & & \\
\hline Família Tipulidae & 3 & & & & & & & & 1 & & & \\
\hline Família Ceratopogonidae & 4 & 1 & & 4 & 1 & & 1 & & 1 & 3 & 1 & \\
\hline Família Psychodidae & & & 1 & & & & & & & & & \\
\hline Família Chaboridae & & & & & & 26 & & & & 8 & & 10 \\
\hline Família Dixidae & & & & & & 2 & & & & & & \\
\hline Família Sciomyzidae & & & & & & & 1 & & & & & \\
\hline Família Phoridae & & & & & & & & & & & 1 & \\
\hline Familia Culicidae & & & & & & 11 & & & & & & \\
\hline \multicolumn{13}{|l|}{ Ordem Ephemeroptera } \\
\hline Família Baetidae & 1 & 3 & & & & 13 & & & & & & \\
\hline Família Caenidae & & 1 & & & & 13 & 1 & & 7 & 48 & 17 & 41 \\
\hline Família Leptohyphidae & & & & & & 8 & & & & & & \\
\hline \multicolumn{13}{|l|}{ Ordem Trichoptera } \\
\hline Família Hydropsychidae & 17 & & & & & 1 & 6 & & & & & \\
\hline \multicolumn{13}{|l|}{ Ordem Lepdoptera } \\
\hline Família Pyralidae & & & & & & 1 & & & 1 & & & 1 \\
\hline \multicolumn{13}{|l|}{ Ordem Coleoptera } \\
\hline Família Haliplidae & & 1 & & & & 1 & & & 5 & & & \\
\hline Família Gyrinidae & & 1 & & & & 2 & & & 2 & 1 & & \\
\hline Família Dytiscidae & & & & & & 1 & & & 3 & & & \\
\hline Família Elmidae & & & & & & & 1 & & & & & \\
\hline Família Staphylinidae & & & & & & & & & & & 1 & \\
\hline \multicolumn{13}{|l|}{ Ordem Hemíptera } \\
\hline Família Corixidae & & & & & & & & & & 1 & 6 & 1 \\
\hline Família Nepidae & & & & & & & & & & 2 & & 1 \\
\hline Família Gerromorpha & & & & 4 & & & & & & & & \\
\hline Família Notonectidae & & & & & & 5 & & & & 7 & & 8 \\
\hline Família Belostomatidae & & & & & & & & & & 3 & & 2 \\
\hline
\end{tabular}

Dentre as famílias identificadas, a família Chironomidae foi a que apresentou a maior abundância em todos os pontos de amostragem, exceto no ponto 5 , período seco, onde a maior abundância foi observada na família Tubificídae e no ponto 4, período chuvoso, onde a maior abundância foi observada na família Caenidae (Figura 5). A maior abundância de Chironomidae nos pontos 1 e 3, período seco, se deve, respectivamente, a tribo Tanytarsini, em geral mais sensível dentre os Chironomidae (ANDERSON et al., 1980; SIMPSON et al., 1980; HILSENHOFF, 1987) e a subfamília Orthocladiinae. Já no ponto 5 , período chuvoso, a maior abundância de Chironomidae se deve a tribo Chironomini e subfamília Tanypodinae (Figura 5).

Dos táxons identificados, dez foram classificados como descritores do ambiente contribuindo com 88\% da abundância total: Dicteriadidae e Libellulidae ambos pertencentes a ordem Odonata, Chironomini, 
Tanypodinae, Orthocladiinae, Tanytarsini todos pertencentes a família Chironomidae e Chaboridae ambos da ordem Díptera, Caenidae (Ordem: Ephemeroptera), Hydropsychidae (Ordem: Trichoptera) e Tubicidae (Ordem: Haplotaxida).

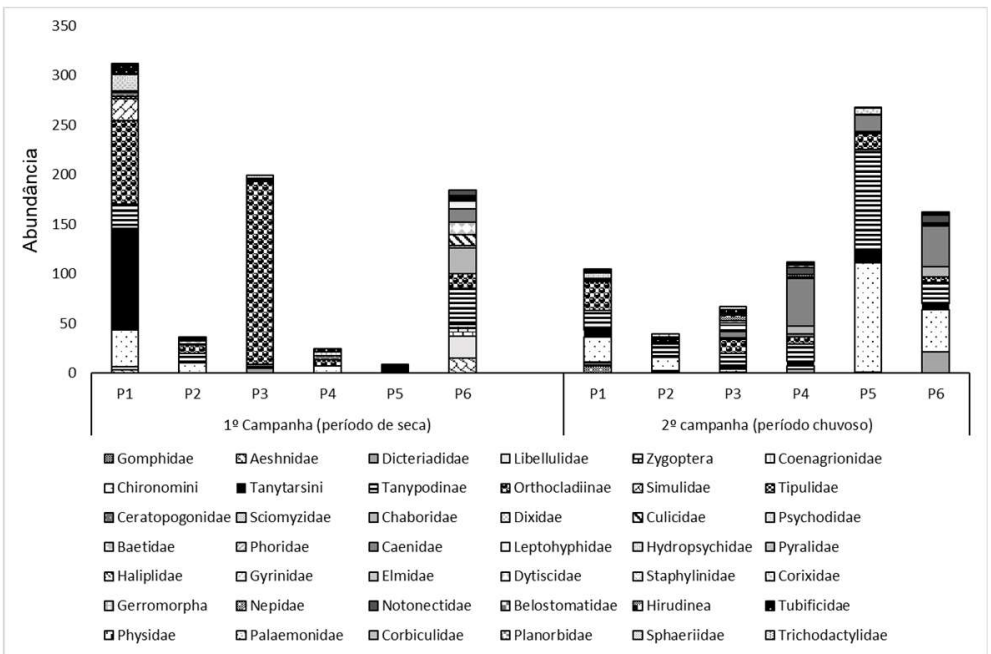

Figura 5: Abundância das famílias da fauna bentônica, durante o período analisado, das 5 sub-bacias hidrográficas que alimentam o Reservatório Tanque Grande.

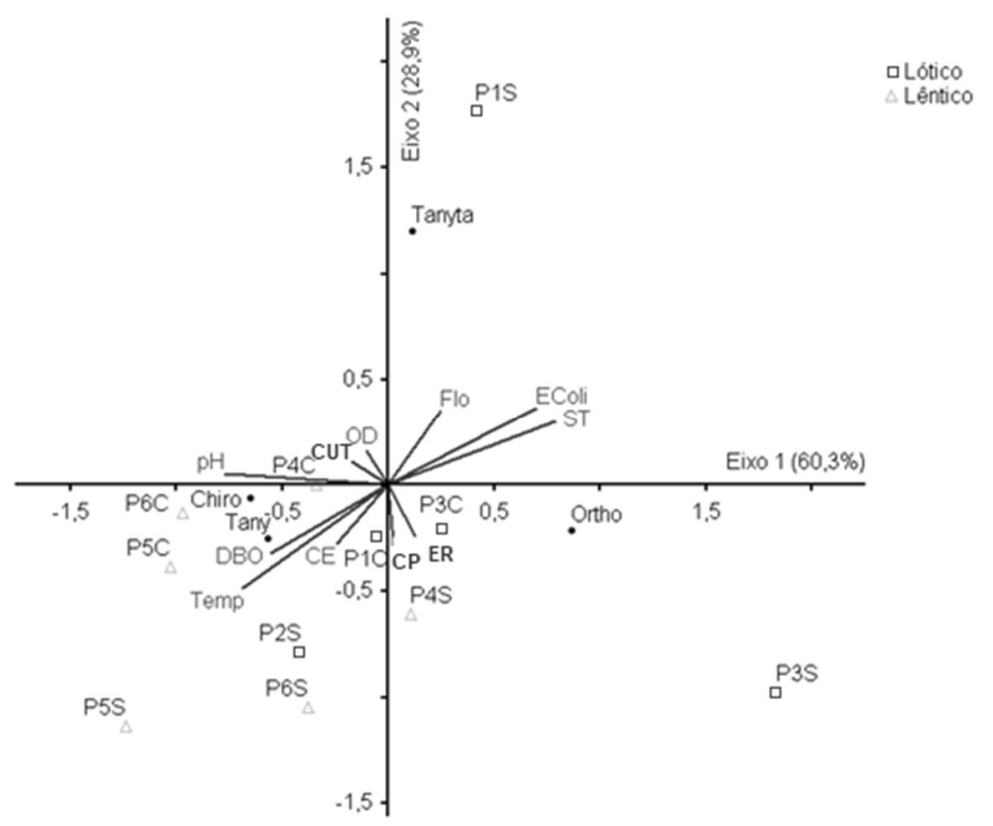

Figura 6: Ordenação pela CCA de seis unidades amostrais das sub-bacias da Bacia Hidrográfica do Tanque Grande e do reservatório Tanque Grande, gerada a partir de quatro táxons descritores do ambiente (Chironomini $=$ Chiro,

Tanypodinae $=$ Tany, Orthocladiinae $=$ Ortho, Tanytarsini $=$ Tanyta) e onze variáveis ambientais (temp = temperatura; $\mathrm{OD}=$ oxigênio dissolvido; $\mathrm{Ph} ; \mathrm{ST}$ = sólido total; $\mathrm{CE}=$ condutividade elétrica, Escherichia coli = E.coli,, Demanda bioquímica de oxigênio $=\mathrm{DBO}$, área florestada $=$ Flo, edificação rural $=\mathrm{ER}$, área com cultivo $=$ CUT e área de Campo $=$ CP).

A análise de correspondência canônica (CCA), utilizando quatro descritores do ambiente e onze variáveis ambientais, explicou 94\% da variabilidade conjunta dos dados nos três primeiros componentes, apresentando autovalor estatisticamente significativo $(p=0,001)$ eixo $1(\lambda 1=0.461)$ e eixo $2(\lambda 2=0,221)$ de acordo com o teste de Monte Carlo. A correlação espécie-ambiente também foi significativa para o eixo 1 da CCA $(p=0,001)$. A correlação intra-set indicou que a E.Coli $(r=0,7)$, os sólidos totais $(S T)(r=0,7)$, a demanda bioquímica de oxigênio (DBO) $(r=-0,5), \mathrm{pH}(r=-0,7)$ e Temperatura $(r=-0,7)$ são as variáveis mais importantes 
na ordenação do eixo 1, enquanto as áreas rural e florestal se destacaram na ordenação do eixo 2 (Figura 6). Do lado positivo do eixo 1 foram ordenadas as unidades amostrais P1 e P3, período seco, correlacionadas as maiores abundâncias da subfamília Orthocladiinae $(r=0,8)$ e as maiores concentrações de $E$. coli e sólidos totais. Enquanto, as unidades amostrais do ponto 5 e 6 foram ordenadas do lado negativo do eixo 1 , associadas as maiores abundâncias da subfamília Tanypodinae $(r=-0,5)$ e da tribo Chironomini $(r=0,6)$ e as maiores temperaturas, DBO e pH. Do lado positivo do eixo 2 foi ordenada a unidade amostral P1, período seco, associada as áreas de floresta $(r=0,4)$ e as maiores abundâncias da tribo Tanytarsini $(r=1,0)$.

\section{DISCUSSÃO}

De maneira geral, os parâmetros analisados na avaliação da qualidade das águas da microbacia Tanque Grande-Montante e do Reservatório Tanque Grande atendem aos limites estabelecidos pela resolução Conama no 357/05 para corpos d'água de classe 1 e são característicos de ambientes oligotróficos (AMAZONAS et al., 2016; OLIVEIRA et al., 2017). No entanto, chama-se a atenção para o fato de que foram registradas altas concentrações de E.Coli e de DBO, em desconformidade com a legislação.

As altas concentrações destes dois parâmetros refletem a degradação ambiental, ainda que sutil, no entorno do reservatório oriunda do uso e ocupação da terra. Essas alterações também foram observadas por Piasentin et al. (2009) nesta mesma área de estudo e, semelhante a esses autores, acredita-se que as atividades do pesqueiro (pesque-pague) e atividades de horticultura e fruticultura situados a montante do ponto 1 e a expansão das edificações rurais (SILVA et al., 2009) ao longo dos pontos 5, 3, 2 e 1 são fatores que contribuem para a degradação das águas. Chama-se a atenção para o fato de que tais condições se agravam em períodos chuvosos, conforme corroborado pela análise da CCA (Figura 6) que demonstrou associação significativa dos altos valores de DBO e temperatura na maioria dos pontos amostrados no período chuvoso. Ribeiro et al. (2013) mencionam que durante o período chuvoso o material alóctone é carreado para dentro dos corpos d'água aumentando a concentração de matéria orgânica, e a demanda de oxigênio molecular requerida pelas bactérias para a decomposição desta matéria orgânica.

Em relação à comunidade de macroinvertebrados, a CCA demonstrou que não houve uma alteração significativa entre ambientes lóticos e lênticos para a colonização dos macroinvertebrados bentônicos. Demonstrou, ainda, que as alterações ambientais observadas nas sub-bacias e no reservatório estudado também se refletiram na comunidade bentônica que apresentaram ampla variação dos valores de riqueza (5 a 19) e baixos valores para diversidade (0.172 a 1.076), em ambos os períodos sazonais, bem como uma maior abundância da família Chironomidae que, de modo geral, são considerados organismos tolerantes às modificações do ambiente (SIQUEIRA et al., 2005).

Callisto et al. (2001), Hepp et al. (2007) e Gamito et al. (2012) mencionam que os atributos de riqueza (S) e diversidade $\left(\mathrm{H}^{\prime}\right)$ quando em altos valores indicam ambiente mais preservado e sinalizam ambiente impactado quando registrados em menor valor, como foi o caso de alguns dos pontos analisados neste trabalho. A maior riqueza de organismos encontrada no período chuvoso (Figura 4), provavelmente, está 
relacionada ao carreamento de material alóctone para o corpo hídrico nesse período. Com o carreamento deste material, a heterogeneidade de substratos se eleva favorecendo o aumento da riqueza de táxons que coloniza estes diferentes habitats (ZARDO et al., 2013).

Díptera, a ordem mais abundante nas sub-bacias estudadas e no reservatório Tanque Grande, está distribuída em larga escala nos ambientes aquáticos de água doce e mostram-se com grande diversidade e abundância, principalmente, por serem, em grande parte, organismos tolerantes às modificações do ambiente, especialmente alguns táxons da família Chironomidae, que neste estudo, atuaram como os principais descritores do ambiente (MACHADO et al., 2015; CORDEIRO et al., 2016).

A maior abundância da tribo Tanytarsini (Chironomidae), mais sensíveis às modificações do ambiente em comparação com os outros representantes da família Chironomidae (ANDERSON et al., 1980; SIMPSON; BODE, 1980; HILSENHOFF, 1987), no ponto 1, período seco, pode ser explicada pela condição natural, do ambiente e corroborado pelas análises da CCA que correlacionou a maior abundância desses organismos nesse ponto a áreas florestadas. No ponto 1, parte do córrego possui uma das margens coberta com mata ciliar e vegetação densa, o que favorece a disponibilidade de alimentos e substratos para a fixação dos macroinvertebrados bentônicos além de outros indivíduos que, no período seco, tornam-se mais estáveis e mais propícios a sua fixação no ambiente. Por outro lado, em períodos chuvosos onde ocorre o carreamento de material alóctone para o corpo hídrico, os organismos mais sensíveis como a tribo Tanytarsini tendem a diminuir sua abundância, conforme observado neste trabalho e coerente com uma situação similar analisada por Poulton et al. (2015).

A maior abundância de Orthocladiinae no ponto 3, durante período seco, considerados organismos indicadores de ambientes mais preservados (BEM et al., 2015), embora associado as maiores concentrações de E.Coli, pode ser atribuída a correnteza da água neste local e as maiores concentrações de Sólidos totais. A alta correnteza favorece ao desenvolvimento destes táxons que possuem capacidade de nadarem através da corrente, o que permite a rápida colonização de substratos e os sólidos totais que quando em suspensão na coluna d'água compõe a base alimentar de organismos como larvas de Orthocladiinae (CUMMINS et al., 2005; BARBOLA et al., 2011; ROSA, 2015).

No ponto 5, a alta abundância de táxons de Chironomini e Tanypodinae no período chuvoso e a presença de Tubificidae podem estar associadas à poluição orgânica, conforme indicado pela análise de CCA que correlacionou significativamente as maiores abundâncias de Chironomini e Tanypodinae às altas concentrações de DBO. Estes resultados refletem o uso e ocupação do entorno marcado pela intensa utilização das águas para fins de lazer e recreação, descarte de material orgânico no entorno e dentro do lago, além de comércio (bar) próximo às margens do reservatório, o que favorece o maior fluxo de pessoas, notadamente nos fins de semana. Ainda corroborando estes dados, Marques et al. (1999) e Roque et al. (2000) mencionam que algumas tribos da família Chironomidae, como Chironomini, são indicadoras do aumento de enriquecimento orgânico oriundo de atividades antrópicas.

Kleine et al. (2005), Martins et al. (2008); Lopes et al. (2015) relatam que alguns grupos da 
macrofauna bentônica, como os Tubificídeos, sobrevivem em condições extremas, como de sobrecarga orgânica no ambiente e que são comuns em áreas mais urbanizadas. No entanto, a simples ocorrência destes táxons não indica a deterioração do ambiente, é sua alta dominância que vai refletir essas mudanças (MARTINS et al., 2017). Por outro lado, a presença de Tubifícideos no ponto 5 pode ser um indicativo do aumento das edificações rurais na região conforme observado ao comparar os dados de uso e ocupação da terra registrados por Silva et al. (2009) aos levantados por esta pesquisa e, consequentemente, alteração do ambiente natural, nos últimos 15 anos.

Embora a maior abundância no ponto 6 tenha sido de Chironomidae, este ponto apresenta-se mais preservado com predominância de área florestada, vegetação ripária às margens do lago e com raros vestígios de antropização em seu entorno. Provavelmente, estes fatores resultaram em uma maior riqueza e diversidade nesse ambiente.

A análise da comunidade de macroinvertevrados bentônicos mostrou-se eficiente na análise ambiental das sub-bacias contribuintes do Reservatório Tanque-Grande. Rosa et al. (2014) mencionam que indivíduos tolerantes, como Chironomidaes e Oligochaeta, tendem a aumentar sua abundância quando as condições dos habitats são favoráveis para o seu desenvolvimento. E que estes só representam um indicativo de degradação, uma vez que tenham uma elevada abundância e a baixa ocorrência de táxons mais sensíveis (FITARELLI et al., 2017), como foi observado neste trabalho.

\section{CONCLUSÕES}

A partir dos resultados obtidos é possível concluir que a análise conjunta dos parâmetros físicos, químicos, biológicos e da comunidade de macroinvertevrados bentônicos se mostrou eficiente na análise ambiental das sub-bacias da Microbacia Tanque Grande-Montante e do Reservatório Tanque Grande. A maioria das variáveis físicas e químicas analisadas, a alta abundância da família Chironomidae e a baixa ocorrência de táxons sensíveis da comunidade de macroivertebrados bentônicos demonstraram que a qualidade da água do ambiente analisado apresenta condições favoráveis com características oligotróficas mas, ainda que sutis, com sinais de degradação e, que está degradação é oriunda de atividades antrópicas, conforme observado pelas análises de uso e ocupação da terra. Este parâmetro demarcou áreas de expansão rural (casas, chácaras, pequenos comércios, piscicultura e criação de animais) e de cultivo na bacia hidrográfica, referenciadas pelas análises físico-químicas que registraram altas concentrações de E.coli e DBO, indicando contaminação por esgoto doméstico 'in natura' e presença de material orgânico nessas águas.

\section{REFERÊNCIAS}

ANA. Agência Nacional de águas. Guia nacional de coleta e preservação de amostra: água, sedimento, comunidades aquáticas e efluentes líquidas. São Paulo: CETESB, 2011.

ANDERSON, R. L.; WALBRIDGE, C. T.; FIANDT, J. T.. Survival and growth of Tanytarsus dissimilis (Chironomidae) exposed to copper, cadmium, zinc, and lead. Archives of Environmental Contamination and Toxicology, v.9, p.329$335,1980$.

ANDRADE, M. R. M.; OLIVEIRA, A. M. S.. Guarulhos tem História: questões sobre a história natural, social e cultural. 
São Paulo: Ananda, 2008.

BARBOLA, I. F.; MORAES, M. F. P. G.; ANAZAWA, T. M.; NASCIMENTO, E. A.; SEPKA, E. R.; POLRGATTO, C. M.; MILLÉO, J.; SCHUHLI, G. S.. Avaliação da comunidade de macroinvertebrados aquáticos como ferramenta para o monitoramento de um reservatório na bacia do rio Pitangui, Paraná, Brasil. Iheringia, Série Zoologia, Porto Alegre, v.101, n.1-2, p.15-23, 2011. DOI: http://dx.doi.org/10.1590/S0073$\underline{47212011000100002}$

BEM, C. C.; HIGUTI, J.; AZEVEDO, J. C. R.. Qualidade da água de um ambiente lótico sob impacto antropogênico e sua comunidade bentônica. RBRH, Porto Alegre, v.20, n.2, p.418429, 2015.

CALLISTO, M.; MORETTI, M. GOULART, M..

Macroinvertebrados bentônicos como ferramenta para avaliar a saúde de riachos. Revta. Bras. Rec. Hid, v.6, n.1, p.71-82, 2001.

CONAMA. Conselho Nacional de Meio Ambiente. Resolução 357/2005. Classificação dos corpos de água. 2005.

CORDEIRO, G. G.; GUEDES, N. M.; KISAKA, T. B.; NARDOTO, G. B.. Avaliação rápida da integridade ecológica em riachos urbanos na bacia do rio Corumbá no Centro-Oeste do Brasil. Taubaté. Rev. Ambient. Água, v.11, n.3, p.702-710, 2016. DOI: http://dx.doi.org/10.4136/ambi-agua.1857

CUMMINS, K. W.; MERRIT, R. W.; ANDRADE, P. C. N.. The use of invertebrate functional groups to characterize ecosystem attributes in selected streams and rivers in south Brazil. Studies on Fauna Neotropical and Environment, v.40, n.1, p.69-89. DOI: http://doi.org.10.1080/01650520400025720

EMBRAPA. Empresa Brasileira de Pesquisa Agropecuária. Contaminação da Água por Nitrato. São Paulo: EMBRAPA, 2002.

ESTEVES, F. A.; LEAL, J. J. F.; CALLISTO, M.. Fundamentos de limnologia. 3 ed. Rio de Janeiro: Interciência, 2011.

FITARELLI, B.. Influência das atividades antrópicas sobre a colonização em substrato artificial por macroinvertebrados bentônicos em rio de baixa ordem no Sul do Brasil. Dissertação (Mestrado) - Universidade Estadual do Oeste do Paraná, Maringá, 2017.

GAMITO, S.; PATRICIO, J.; NETO, J. M.; TEIXEIRA, H.; MARQUES, J. C.. Feeding diversity index as complementary information in the assessment of ecological quality status. Ecological Indicators, v.19, p.73-78, 2012.

GOULART, M.; CALLISTO, M.. Bioindicadores de qualidade de água como ferramenta em estudos de impacto ambiental. Revista da FAPAM, v.2, n.1, 2003.

HAMADA, E. N.; NESSIMIAN, J. L.; QUERINO, R. B.. Insetos aquáticos na Amazônia brasileira: taxonomia, biologia e ecologia. Manaus: INPA, 2014.

HEPP, L. U.; RESTELLO, E. M.. Macroinvertebrados bentônicos como bioindicadores da qualidade das águas do Alto Uruguai Gaúcho. In: ZAKRZEVISKI, S. B.. Conservação e uso sustentável da água: múltiplos olhares. Erechim:
Edifapes, 2007, p.75-86.

HILSENHOFF, W. L.. An improved biotic index of organic stream pollution. The Great Lakes Entomologist, v.20, p.3139, 1987.

INMET. Instituto Nacional de Meteorologia. Pesquisa em atividades Meteorológicas. Brasília: INMET, 2017.

ESRI. Instituto de Pesquisa de Sistemas Ambientais. ArcGIS profissional GIS para desktop, versão 10.3. Osasco: Redlands, 2014.

KLEINE, P.; TRIVINHO-STRIXINO, S.. Chironomidae and other aquatic macroinvertebrates of a first order stream: community response after habitat fragmentation. Acta Limnol. Bras., v.17, n.1, p.81-90, 2005.

LOBO, E. A.. Use of epilithic diatoms as bioindicators from lotic systems in southern Brazil, with special emphasis on eutrophication. Acta Limnol, Bras., v.16, n.1, p.25-40, 2004.

LOPES, M. P.; MARTINS, R. T.; SILVEIRA, L. S.; ALVES, R. G.. The leaf breakdown of Picramnia sellowii (Picramniales: Picramniaceae) as index of anthropic disturbances in tropical streams. Braz. J. Biol., v.75, p.846-853, 2015.

MACHADO, N. G.; NASSARDEN, D. C. S.; SANTOS, F.; BOAVENTURA, I. C. G.; PERRIER, G.; SOUZA, F. S. C.; MARTINS, E. L.; BIURDES, M. S.. Chironomus larvae (Chironomidae: Diptera) as water quality indicators along an environmental gradient in a neotropical urban stream. Revista Ambiente Água, v.10, n.2, p.298-309, 2015. DOI: http://dx.doi.org/10.4136/ambi-agua.1533

MARQUES, M. G. S. M.; FERREIRA, R. L.; BARBOSA, F. A. R.. Acomunidade de macroinvertebrados aquáticos e características limnológicas das lagoas carioca e da barra, Parque Estadual do Rio Doce, MG. Revista Brasileira de Biologia, v.59, n.2, p.201-210, 1999. DOI: http://dx.doi.org/10.1590/S0034-71081999000200004

MARTINS, R. T.; COUCEIRO, S. R. M.; MELO, A. S.; MOREIRA, M. P.; HAMADA, N.. Effects of urbanization on stream benthic invertebrate communities in Central Amazon. Ecological Indicators, v.73, p.480-491, 2017.

MARTINS, R. T.; STEPHAN, N. N. C.; ALVES, R. G.. Tubificidae (Annelida:Oligochaeta) as an indicator of water quality in an urban strem in southeast Brazil. Acta Limnol. Bras., v.20, n.3, p.221-226, 2008.

MEDEIROS, S. R. M.; CARVALHO, R. G.; SOUZA, L.; BARBOSA, A. H. S.. Índice de qualidade das águas e balneabilidade no Riacho da Bica, Portalegre, RN, Brasil. Rev. Ambient. Água, Taubaté, v.11, n.3, 2016. DOI:

http://dx.doi.org/10.4136/ambi-agua.1833

MORAES, C. L.. Macroinvertebrados bentônicos na avaliação da qualidade da água do reservatório Tanque Grande, Guarulhos, SP. Dissertação (Mestrado em Análise Geoambiental) - Universidade Guarulhos, 2019.

MUGNAI, R.; NESSINIAN, J. L.; BAPTISTA, D. F.. Manual de Identificação de Macroinvertebrados Aquáticos do Estado do Rio de Janeiro. Rio de Janeiro: TECHNICLBOOKS, 2010 
MCCUNE B.; MEFFORD, M. J.. Multivariate analysis of ecological data: Version 6.0 MjM Software. Gleneden Beach, 2011.

OLIVEIRA, A. M. S.; ANDRADE, M. R. M.; QUIRÓS, N.. Diagnóstico ambiental para manejo sustentável do Núcleo Cabuçú do Parque Estadual da Cantareira e áreas vizinhas do Município de Guarulhos. 2005.

OLIVEIRA, S. A.; BICUDO, C. E.. Seasonal variation of limnological features and trophic state index of two oligotrophic reservoirs of southeast Brazil. Brazilian Journal Biology, v.77, n.2, p.323-331, 2017. DOI: http://dx.doi.org/10.1590/1519-6984.14015

PIASENTIN, A. M.; SEMENSATTO JUNIOR, D. L.; SAAD, A. R.; MONTEIRO JUNIOR, A. J.; RACZKA, M. F.. Índice de Qualidade da Água (IQA) do Reservatório Tanque Grande, Guarulhos (SP): Análise sazonal e efeitos do uso e ocupação do solo. Geociências, São Paulo, v.28, n.3, p.305-317, 2009.

PIRES, D. A.; TUCCI, A.; CARVALHO, M. C.; LAMPARELLI, M. C.. Water quality in four reservoirs of the metropolitan region of São Paulo, Brazil. Acta Limnologica Brasiliensia, v.27, n.4, p.370-380, 2015. DOI: http://dx.doi.org/10.1590/S2179-975X4914

POULTON, B. C.; GRAHAM, J. L.; RASMUSSEN, T. J.; STONE, M. L.. Responses of Macroinvertebrate Community Metrics to a Wastewater Discharge in the Upper Blue River of Kansas and Missouri, USA. Journal of Water Resource and Protection, v.7, p.1195-1220, 2015. DOI: http://dx.doi.org/10.4236/jwarp.2015.715098

RIBEIRO, E. A.; SANDRI, D.; BOÊNO, J. A.. Qualidade da água de córrego em função do lançamento de efluentes de abate de bovinos. Revista Brasileira de Engenharia Agrícola e Ambiental, v.17, n.4, p.425-433, 2013.

ROSA, B.. Estudo da assembleia de Chironomidae (Diptera) para avaliação ecológica de riachos de baixa ordem, Minas Gerais. Tese (Doutorado em Ecologia) - Universidade Federal de Juiz de Fora, 2015.

ROSA, B. F. J. V.; RODRIGUES, L. F. T.; OLIVEIRA, G. S.; ALVES, G.. Chironomidae and Oligochaeta for water quality evaluation in na urban river in southeastern Brazil. Environmental monitoring and assessment, v.186, n.11, p.7771-7779, 2014.

SAAD, A. R.; SEMENSATTO JUNIOR, D. L.; AYRES, F. M.; OLIVEIRA, P. E.. Índice de Qualidade da Água - IQA do
Reservatório do Tanque Grande, município de Guarulhos, Estado de São Paulo, Brasil: 1990-2006. Revista UnG -

Geociências, v.6, n.1, p.118-133, 2007.

SANTOS, S. A. D.. Tanque Grande: Um espaço em Transformação. Estudo da Região Tanque Grande/Guarulhos: Área de Proteção de Mananciais. Dissertação (Mestrado em Geografia) - Universidade Estadual de Campinas, Campinas, 2005.

SCHILLER, A. P.; KUNH, A.; MANFRIN, J.; FERRONATO, M. C.; SCHWANTES, D.; LEISMANN, E. A. V.; JUNIOR, A. C. G.. Bioindicadores de qualidade de água como ferramenta de impacto ambiental de uma bacia hidrográfica. R. gest. sust. ambient., Florianópolis, v.6, n.3, p.165-180, 2017. DOI: http://doi.org/10.19177/rgsa.v6e32017165-180

SHANNON, C. E.; WEAVER, W.. The mathematical theory of communication. Urbana: University of Illinois Press, 1963.

SILVA, C.. Análise Geoambiental do delta do assoreamento do reservatório Tanque Grande, Guarulhos/SP. Dissertação (Mestrado em Análise Geoambiental) - Universidade Guarulhos, 2009.

SIMPSON, K. W.; BODE, R. W.. Common larvae of Chironomidae (Diptera) from New York State streams and rivers with particular reference to the fauna of artificial substrates. Bulletin of New York State Museum and Science Service, New York, v.439, p.1-105, 1980.

SIQUEIRA, T; TRIVINHO-STRIXINO, S.. Diversidade de Chironomidae (Diptera) em dois córregos de baixa ordem na região central do Estado de São Paulo, através da coleta de exúvias de pupa. Rev. Bras. Entomol., v.49, n.4, 2005. DOI: http://doi.org/10.1590/s0085-56262005000400013

SOMMER, U.; PADISÁK, J.; REYNOLDS, C.S.; JUHÁSZ-NAGY, $P$.. Hutchinson's heritage: the diversity-disturbance relationship in phytoplankton. In: PADISÁK, J.; REYNOLDS, C. S.; SOMMER, U.. Intermediate disturbance hypothesis in phytoplankton ecology. Belgica: Kluwer Academic Publishers, 1993. p.1-7.

TUNDISI, M. T.; TUNDISI, J. G.. Liminologia. São Paulo: Oficina de textos. 2008.

ZARDO, D. C.; HARDOIM, E. L.; AMORIM, R.; MALHEIROS, C. H.. Variação espaço-temporal na abundância de ordens e famílias de macroinvertebraos bentônicos registrados em áreas de nascente, Campo Verde/MT. Revista Brasileira Multidisciplinar, v.16, n.1, 2013. DOI: http://doi.org/10.25061/2527-2675/rebram/2013.v16i1.42

A CBPC - Companhia Brasileira de Produção Científica (CNPJ: 11.221.422/0001-03) detém os direitos materiais desta publicação. Os direitos referem-se à publicação do trabalho em qualquer parte do mundo, incluindo os direitos às renovações, expansões e disseminações da contribuição, bem como outros direitos subsidiários. Todos os trabalhos publicados eletronicamente poderão posteriormente ser publicados em coletâneas impressas sob coordenação da Sustenere Publishing, da Companhia Brasileira de Produção Científica e seus parceiros autorizados. Os (as) autores (as) preservam os direitos autorais, mas não têm permissão para a publicação da contribuição em outro meio, impresso ou digital, em português ou em tradução. 